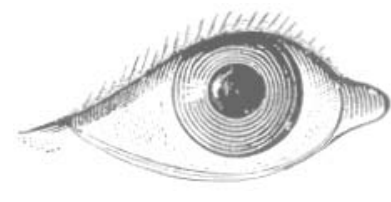

Fernando C. Bolivar Galiano Profesor Asociado del Departamento de Pintura. Facultad de Bellas Artes de Granada.

\title{
LOS AGENTES DE BIODETERIORO DEL PATRIMONIO PICTÓRICO, TEXTIL Y GRÁFICO
}

Los bienes culturales pictóricos, el arte textil y los documentos gráficos tienen en común el estar constituidos, en general, por sustancias orgánicas de diversa naturaleza. La más abundante y conocida es la celulosa, que aparece como elemento mayoritario en las pinturas sobre tabla, la inmensa mayoría de los lienzos, las sargas, las obras textiles de fibra vegetal, los libros y las obras artísticas con soporte de papel. La macromolécula celulosa está formada por cadenas de glucosa que no pueden ser destruidas (asimiladas por hidrólisis) si no se cuenta con los enzimas específicos para ello (celulasas).

Aristóteles de Estagira ya nos hablaba de la gran tendencia de los organismos a ocupar y aprovechar todos los sustratos existentes. En este sentido, si la celulosa es la sustancia orgánica más abundante del planeta, es lógico que exista una gran diversidad de organismos capaces de degradarla. Es el caso de bacterias, hongos, protozoos e insectos que por sí solos, o con la ayuda de asociaciones simbióticas, pueden utilizar esta energía que en caso contrario quedaría inútilmente almacenada.

Por el contrario, las proteínas que constituyen las fibras animales (queratina, colágeno, fibroina, sericina...) de las pinturas sobre seda o lana, los aglutinantes de huevo o cola tradicional, los tapices, las alfombras, las vestimentas litúrgicas o antiguas, los pergaminos y las encuadernaciones de cuero son de más difícil aprovechamiento por parte de los organismos. Esto no ha impedido que numerosos organismos se especialicen en su asimilación. Podemos considerar tres grupos bien diferenciados.

\section{MICROORGANISMOS (bacterias, actinomicetos y hongos)}

Serían los organismos unicelulares o aquellos que son observables sin medios ópticos. Los géneros bacterianos más frecuentes son: Pseudomonas, Vibrio, Bacillus, Bacterium, Cellulomonas, Clostridium y Micrococcus. Se han encontrado también algunas bacterias patógenas para el hombre, como el bacilo de la tuberculosis (Mycobacterium tuberculosi), Bacillus anthracis y Escherichia coli, que de forma más o menos accidental son capaces de alterar las propiedades de los materiales celulósicos.

El orden de bacterias llamado Actynomicetales, se considera por separado por ser un grupo con características afines a los hongos. Los géneros más notables son: Actinomyces y Streptomyces.

Los hongos son microorganismos que proliferan rápidamente cuando las condiciones lo permiten (desgraciadamente muy a menudo en los ambientes donde se guarda o amontona la mayor parte de nuestro patrimonio cultural en papel). Son capaces de fermentar la celulosa que constituye el papel y provocar diversos daños como: pigmentaciones, disgregaciones, lagunas, etc. Dentro de los Deuteromicetes (hongos imperfectos) los géneros más encontrados son Phoma, Pestalotia, Botryotrichum, Sporotrichum, Verticillium, Torula, Cladosporium y Fusarium. Los Ascomicetes más frecuentes son Aspergillus, Penicilium, Chaetomium, Sclerotinia y Phragmonaevia. Los Basidiomicetes (los hongos más evolucionados) son menos frecuentes sobre papel, destacando algunos géneros del orden Poriales: Merulius, Coniophera y Poria.

Métodos de diagnosis y cultivo de microorganismos

Para determinar si las causas de deterioro son de origen biológico e incluso qué tipo de bioagente está actuando, debemos hacer uso de diversas técnicas microscópicas, fisiológicas y bioquímicas. Para una correcta identificación puede ser necesaria la realización de cultivos axénicos enriquecidos con medios específicos que favorecen el crecimiento de determinadas especies. Estos cultivos pueden hacerse en medios líquidos, dentro de matraces, o en medios sólidos utilizando placas de Petri con agar-agar o silicagel (que no aporta ninguna fuente de carbono). Una vez introducido el inóculo, los cultivos son mantenidos en cámaras de cultivo con temperatura, humedad y luz controladas. Es conveniente purificar los cultivos mediante resiembras con pipeta Pasteur. Las reacciones bioquímicas y fisiológicas derivadas del uso de medios selectivos con indicadores, e incluso con antibióticos nos pueden ser de gran ayuda si se requieren determinaciones precisas.

Para una primera aproximación nos pueden ser útiles los caracteres color y forma de las colonias y a continuación la forma y agrupación de las células, así como el empleo de tinciones diferenciales como la de Gram, Ziehl-Nelsen, etc. Para la observación de la superficie de las células y los agregados, así como de los efectos causados en los materiales artísticos 
a ensayar, es necesaria la microscopia electrónica de barrido.

\section{INVERTEBRADOS (artrópodos y moluscos)}

Los daños causados por organismos animales son de gran importancia, ya que pueden constituir plagas de difícil erradicación. El filo de los artrópodos es el más importante ya que agrupa a insectos (hexápodos celulosófagos) y crustáceos (isópodos oniscoideos), además de típicos predadores como los arácnidos y los miriápodos. Para su estudio se utilizan distintos medios ópticos que van desde las lupas de campo de 10 ó 16 aumentos, las lupas binoculares, el tesovar, y los microscopios ópticos y electrónicos.

La simbiosis es la forma más habitual que tienen los insectos para degradar la celulosa. Se pueden establecer tres estrategias diferentes para su asimilación:

a. Presentando protozoos en sus estómagos o sus tractos intestinales (Joenia, Devescovinia...) que a su vez cuentan con bacterias espirales o bacilares que efectúan la hidrólisis. Es el caso de los escarabajos Anóbidos, las termitas inferiores (como Kalotermes), las cucarachas y los lepismátidos.

b. Sintetizando los enzimas (celulasas), es el caso de los Cerambícidos como el capricornio doméstico (Hylotrupes bajulus).

c. Cultivando hongos a partir de esporas. Es el caso de los escarabajos de la ambrosía o Escolítidos que producen el daño cuando la madera está aún sin cortar, y las termitas superiores (como Reticulitermes) que disponen de plantaciones de hongos en los habitáculos subterráneos de la colonia.

d. Por último, los que no son capaces de fermentar la celulosa pero pueden alimentarse de los reservorios de almidón de las células vegetales (especialmente en las maderas curadas de forma rápida con altas temperaturas). A este grupo pertenecen los escarabajos Lictidos, llamados vulgarmente escarabajos del polvo de los postes (Lyctus brunneus).

\section{VERTEBRADOS (refiriéndonos a aves y mamíferos)}

De todos los efectos causados por animales superiores son los factores antropogénicos los de mayor importancia, como el uso, las causas intrínsecas de deterioro, derivadas de malas técnicas de ejecución y el uso de materiales defectuosos, del vandalismo, los tratamientos agresivos, la reutilización, etc. Además, aquí se incluyen los efectos de desamilación por parte de aves gregarias (Columba livia, Passer domesticus, Larus argentatus, Stumus unicolor, Corvus monedula) y mamíferos voladores (murciélagos como Pipistrellus pipistrellus), destacando la acción mecánica de los roedores que a menudo dañan los tejidos, las pinturas y los documentos gráficos para abrirse paso, desgastar sus incisivos y aportar material aislante a sus nidos.

Las formas de deterioro relacionadas con los agentes de biodeterioro del patrimonio pictórico, textil y gráfico pueden ser de tipo cromático: manchas, unciones, oxidaciones, foxing (moteados de color zorro rojo); depósitos: materia orgánica, crecimiento de microorganismos; pérdidas: disgregaciones, pulverulencias, grandes faltas, orificios; rupturas: grietas, rajas a bisel; deformaciones: alabeos, combamientos, arrugas, abolsados, ampollas. En el caso de libros además: alteraciones del cuero, guardas y colas.

En conclusión, las obras de arte pictóricas, textiles y las realizadas en papel suelen presentar diversas alteraciones provocadas por uno o varios de los agentes de biodeterioro conocidos, especialmente si han estado sometidas a condiciones termohigrométricas elevadas, como es el caso de numerosos archivos y bibliotecas e incluso de algunos museos, conjuntos monumentales, iglesias y domicilios particulares. Es evidente que conociendo con exactitud la causa del daño, podremos efectuar un tratamiento más coherente y proponer las condiciones de mantenimiento precisas para reducir o evitar riesgos en el futuro.

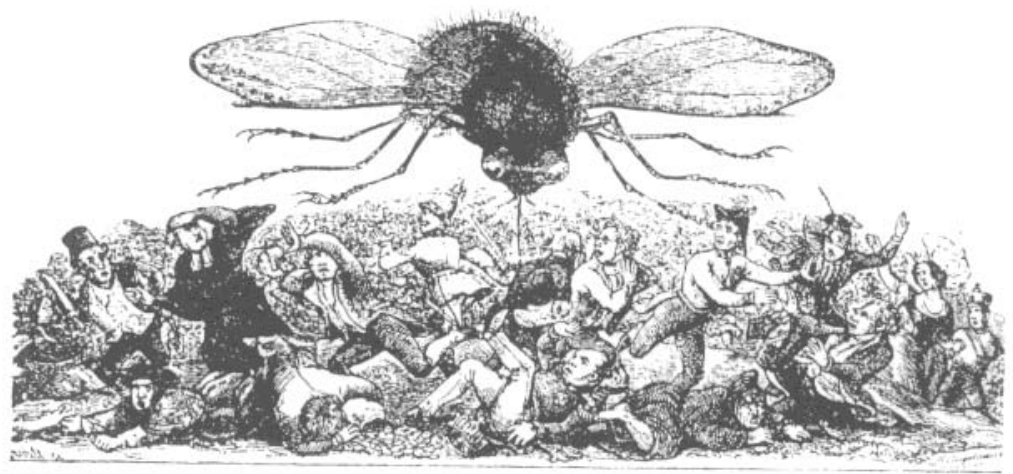

